
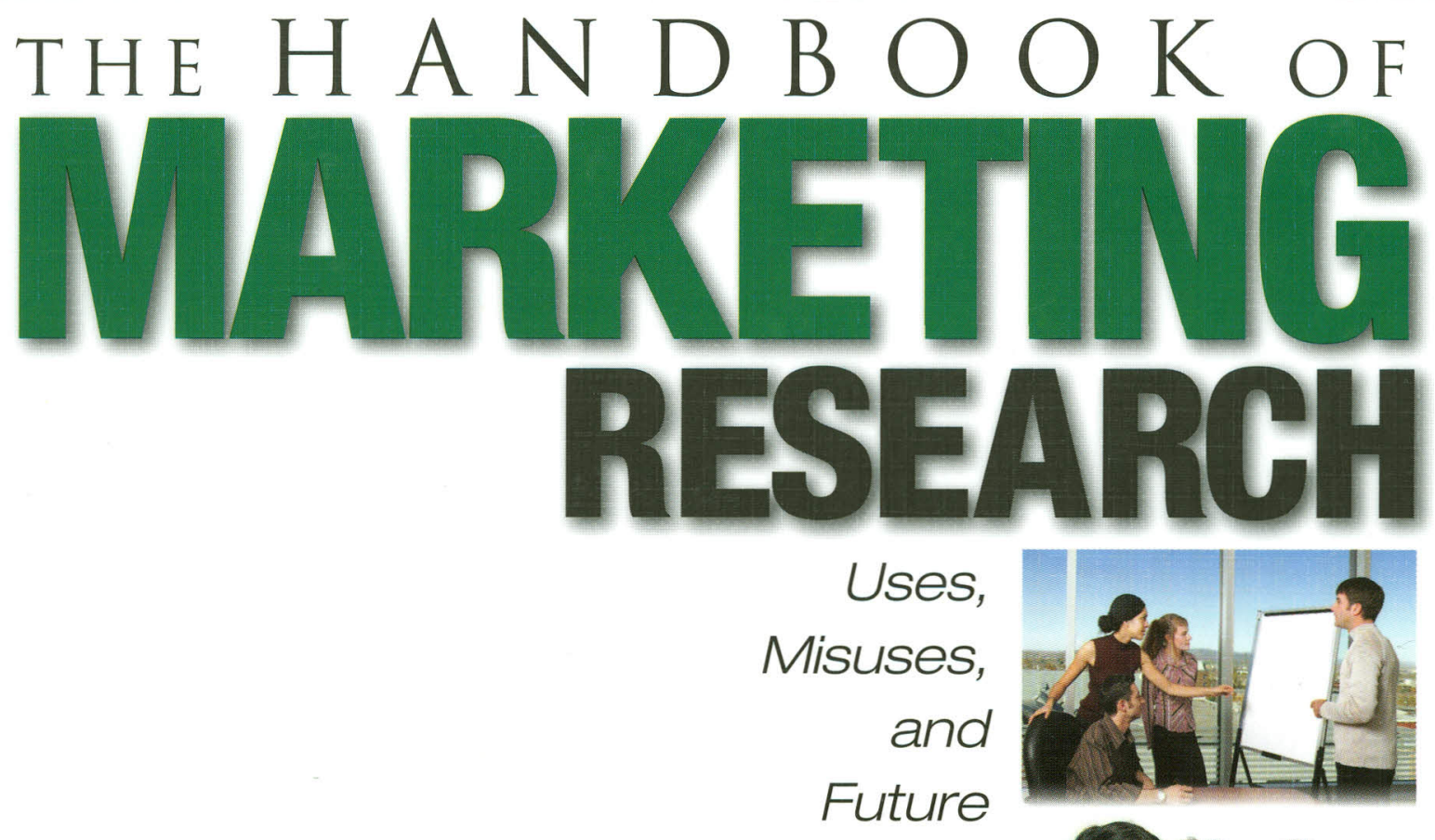
Advances
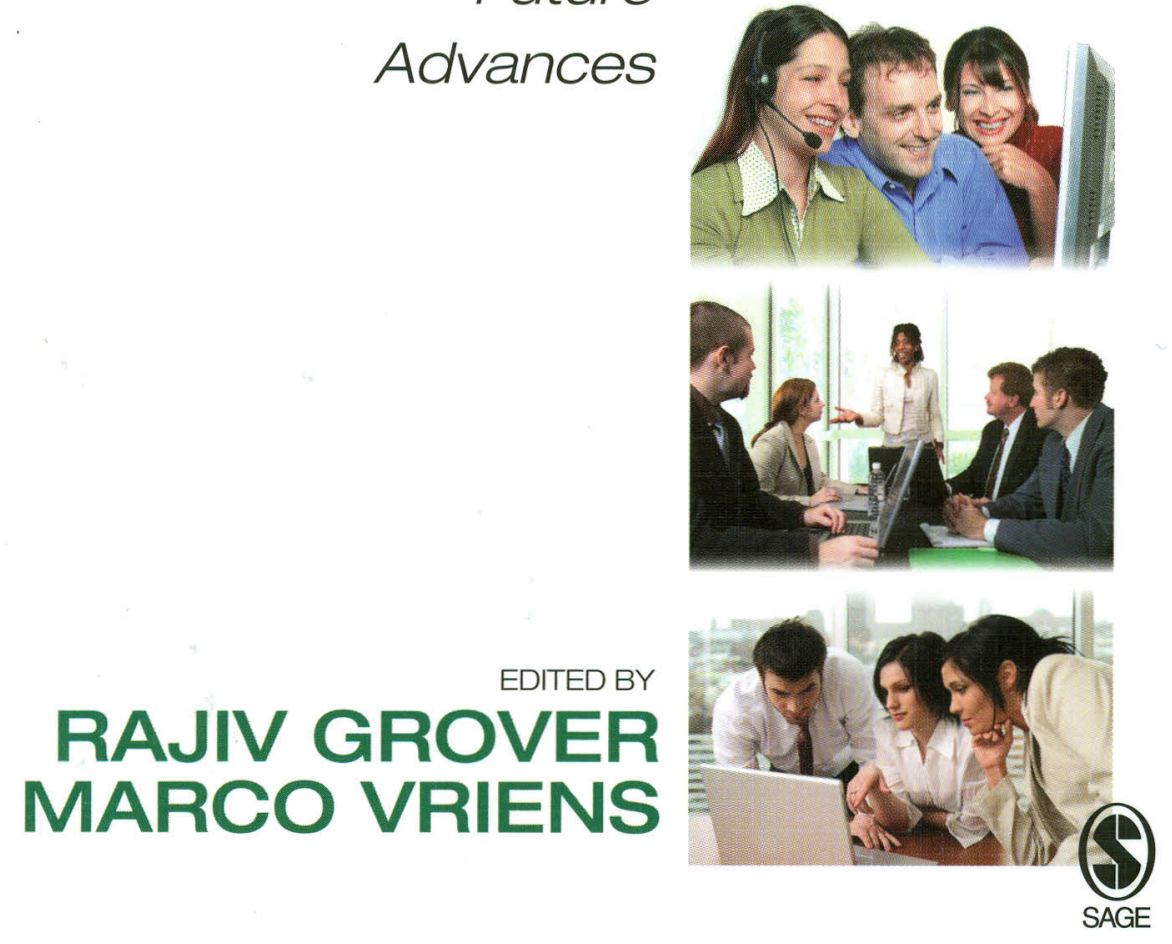


\title{
31
}

\section{Marketing Management SUPPORT SySTEMS AND THEIR IMPLICATIONS FOR MARKETING RESEARCH}

\author{
Gerrit H. Van Bruggen \\ RSM Erasmus University \\ BEREND WIERENGA \\ RSM Erasmus University
}

$\mathrm{M}$ arketing decision makers are responsible for the design and execution of marketing programs for products or brands. They operate under different names, such as product manager, brand manager, marketing manager, marketing director, or commercial director. They choose the target markets and segments for their products and services and develop and implement marketing mixes. Because of the proliferation of products and brands, the fragmentation of markets in an ever growing number of different segments, the fierceness of competition, and the overall acceleration of change, marketing decisions are becoming increasingly complex. Furthermore, decisions have to be made under increasing time pressure. Product life cycles are getting shorter, and competition occurs not only within countries but also increasingly at an international and even global level. New markets are rapidly opening up, existing markets are being deregulated, and new distribution channels such as the Internet have developed. The question now is, how can these decision makers be supported to become more effective?

Today there is a rich collection of tools that can help marketing managers improve the quality of their decisions. Decision aids such as marketing information systems, marketing models, marketing expert systems, marketing neural networks, and so on have been developed and implemented in companies. The term marketing management support systems (MMSSs) refers to this collection of tools.

The effective use of MMSSs is important because the gathering and transforming of information into actionable marketing knowledge is of utmost strategic value. MMSSs can be considered as the link between marketing decision making/management and marketing research because they act as channels through which the 
results of marketing research can be brought to bear on marketing decision making in practice.

Research in marketing science and in computer science has produced a large and sophisticated set of tools that support marketing management and decision making. In this chapter, we present an overview of the various types of MMSSs that are currently available. Furthermore, we present a model for the effective implementation and use of MMSSs. Finally, we discuss how marketing research can contribute to achieve the best results from marketing management support systems.

Our basic proposition is that to be effective, an MMSS should match with the decision situation it is supposed to support. To do so, MMSSs should match with the thinking and reasoning processes of managers. System developers should start with investigating the way that decision makers solve problems and then develop systems that match with this problem-solving mode. We believe that, so far, MMSSs in practice have not fully realized their potential. One reason for this may be that the systems that are being implemented are not sufficiently aligned to the decision situation they are supposed to support.

\section{The Characteristics and Demands of Marketing Decision Making}

Marketing managers ${ }^{1}$ are exposed to a constant stream of information about the markets they are operating in and the performance of their products. This information consists of data from formal information systems and market research studies as well as informal (often qualitative) cues about customers, distributors, competitors, and so forth. Especially with consumer goods, the amounts of data collected using customer cards and point-of-sales scanning technology have multiplied. After the "scanner revolution" came the Internet, which is an incredible source of consumer data, not only purchase data but also consumer Web visit and Web behavior data. But also in business-to-business (B-to-B) markets, the amount of data is quickly increasing. Many B-to-B companies have customer relationship management (CRM) systems in place these days. The core element of a CRM system is a database with data on individual customers and their purchasing history and on the company's marketing activities. Furthermore, in B-to-B markets, electronic commerce is becoming quickly the dominant form of marketing, which generates a lot of data on transactions and interactions with customers.

Usually, marketing decision makers bring a substantial amount of knowledge to bear on solving their problems. Skillful marketers make the best of the interplay between (hard) data and (soft) knowledge. However, they simultaneously cope with cognitive limitations that may inhibit them from optimally processing all the information and knowledge that is available. Therefore, the exponential growth of available information offers great opportunities for marketers, but it also has its downside. The question we face is how marketing decision makers deal with the complexities and dynamics of the environments they are operating in.

\section{Marketing Problem-Solving Modes}

In his book on cognitive science, JohnsonLaird (1988) observes that "human cogitation occurs in dazzling variety" (p. 217). At one extreme there is "mental arithmetic," where people deliberate and calculate in a consciously controlled way and where calculations have a goal and are deterministic. He calls this "the clocks of mind." At the other extreme, there is the free flow of thoughts (dreams), mental processes without a goal, and varieties of creation, which he calls "the clouds of mind."

Assuming that the thought and reasoning processes of marketing managers are not different from those of ordinary humans, we present a typology of marketing problem-solving modes, which represent the different positions between these clocks and clouds of the mind (for a more detailed discussion, see Wierenga \& Van Bruggen, 2000). Specifically, we distinguish four different modes, summarized in the acronym ORAC: Optimizing, Reasoning, Analogizing, and Creating (see Figure 31.1). These four marketing problem-solving modes (MPSMs) are ordered from hard optimization by means of exact calculations to soft associations and creativity. 


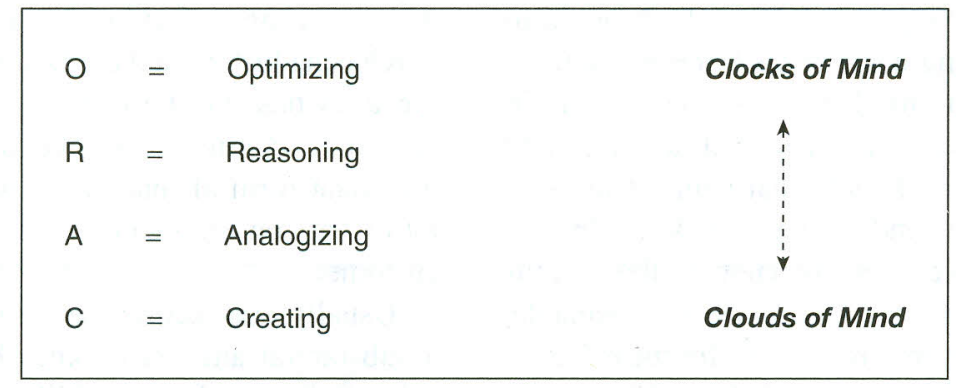

Figure 31.1 The ORAC Model of Marketing Problem-Solving Modes

\section{Optimizing}

The cognitive model of a marketing manager using the optimizing mode is that of a scientist or engineer who has a clear understanding of how marketing processes work. This is represented by a mathematical model, which describes the relationships between the relevant variables in a quantitative way. The decision maker searches for those values of the decision variables that maximize the goal variable(s) for the particular problem. These optimal values for the decision variables are determined in the "model world." Next, they are translated into the "real world." In other words, a marketing management problem is converted into a "marketing programming problem" (Kotler, 1971).

To solve a marketing programming problem, two basic requirements exist: (a) a model describing the mechanism underlying the marketing problem or phenomenon and (b) an optimization algorithm that searches for the optimal values for the decision variables given the objective (e.g., profit maximization or $50 \%$ brand awareness). In the early days of optimization in marketing, the emphasis was on the optimization procedure. If an optimization procedure was available (e.g., linear programming), one was even willing to "adapt" the marketing problem somewhat, so that it would fit the properties of the algorithm. A case in point is the application of linear programming to media planning, where the relationship between the effect of an advertisement and the number of insertions was taken to be linear, not because of theoretical reasons but because it fitted the model so nicely. Later, however, it became clear that it is much more important to have a correct model of the marketing phenomenon under study (since increasing computer capacity has made it almost always possible to carry out the optimization by some form of simulation). This gave rise to a model-building tradition, which became a prominent school in marketing (science).

\section{Reasoning}

It has long been recognized that individuals form and use mental representations of phenomena in the outside world. Such representations are called mental models. A mental model is a symbolic structure, a representation of a body of knowledge in the human mind (Johnson-Laird, 1988, 1989). A person can use such a mental model for reasoning about a phenomenon. In cognitive science, this type of approach to a problem is called model-based reasoning (Forbus, 1988; Hayes, 1985; Johnson-Laird, 1989).

In the optimizing mode, it is assumed that there is an objective model that provides a valid description of the marketing phenomenon under study. However, only a small part of all marketing phenomena has been brought under scientific scrutiny, so our systematic, scientifically based knowledge of marketing phenomena is limited. If a systematic world underlying marketing phenomena exists at all, it has been explored and mapped out only incompletely. In the absence of an objective model, a marketer often adopts the marketing problem-solving mode called reasoning. In the reasoning mode, decision makers construct a representation of the marketing phenomenon in their minds. These mental models are then the basis for the manager's reasoning about the problem. A mental model consists of variables deemed 
relevant and the supposed cause-and-effect relationships between these variables. Such a model helps a decision maker to diagnose and solve a specific problem.

Different marketing managers may have different mental models with respect to the same phenomenon. For example, in the case of advertising, different marketing managers may use different models to explain why a particular advertising campaign was successful. A marketer's mental model of a specific phenomenon is shaped by experience in practice, sometimes after a theoretical education. In the optimizing mode, marketers also have a mental model of the situation. Compared to this model, the mental model in the reasoning mode is more qualitative, subjective, and incomplete.

\section{Analogizing}

When confronted with a problem, a person has a natural inclination to bring to bear the experience gained from solving similar problems in the past. A doctor, faced with a patient who has an unusual combination of symptoms, may remember another patient with similar symptoms and propose the same diagnosis as in the previous case (Kolodner, 1993). Analogizing is considered a fundamental mechanism in human understanding and problem solving. "Analogy-making lies at the heart of intelligence" (Hofstadter, 1995, p. 63). Children automatically apply analogical thinking, and some elements of analogical thinking can even be found in apes and chimpanzees (Holyak \& Thagard, 1995).

For a long time, the "general problem-solving" school was dominant in cognitive science. According to this school, human thought depends on a set of reasoning principles that are independent of any given domain - meaning that we (humans) reason the same way no matter what we are reasoning on or about. Simon (1979) formulated this (standard) way of operating by "Thinking Man" as follows: "Thinking is a process of serial selective search through large spaces of alternatives guided by individual mechanisms that operate through dynamically adapting aspiration levels" (p. xii). The proponents of analogical reasoning have a very different view (Riesbeck \& Schank, 1989): “Certain aspects of human thought may be a simpler affair than many scientists have imagined" (p. 3). In other words, human problem-solving behavior can often be explained by much simpler mechanisms than the general problem solver.

Analogical (or case-based) reasoning implies that the original concrete instances are used for reasoning, rather than abstractions based on those instances. One might deduce general principles from the experienced cases, but according to Riesbeck and Schank (1989), such "general principles are impoverished compared to the original experience." After many repetitions of the same situation, some cases may "coalesce" into rules. However, these rules are encoded in memory separate from any particular instance of their use or the history of their creation.

Wide support exists for analogical reasoning as a model for human decision making. Studies in human problem solving reveal the pervasiveness of analogy usage (Sternberg, 1977). People find analogical reasoning a natural way to reason. Car mechanics, physicians, architects, and caterers use it. In particular, case-based reasoning excels as an approach to "weak-theory domains," domains where phenomena are not understood well enough to determine causality unambiguously.

Indeed, much of marketing problem solving probably follows the analogizing path. A marketing manager usually has a set of experiences (cases) available from memory, referring to all kinds of marketing events: new-product introductions, price changes, sales promotions, advertising campaigns, reactions of competitors, and so on. In a new situation, even without active effort on the part of the manager, one or more earlier situations come to mind that resemble the current one. Sometimes, the manager will be inclined to choose the same kind of solution as in the previous case. For example, a manager may decide to execute the same sales promotion for a product in Country B as the one that was so successful in Country A earlier. However, in many cases, the manager will not literally repeat the previous solution but will adapt it somewhat. In a sales promotion, for example, the specific premium and packaging used in Country B may differ from those used in Country A. Hoch and Schkade (1996) found that to arrive at a forecast, decision makers often 
search their experience for a situation similar to the one at hand and then make small adjustments to it.

Basically, in these situations, a process of analogizing or analogical reasoning takes place. For most problems, marketing theory is insufficient ("weak-theory domain"). Marketing managers often have no generalized rules, drawn from experience, that could serve as elements of a mental model. However, managers do have a lot of experience with more or less similar cases. Moreover, in many instances, there simply is not enough time to solve a problem by reasoning from "first principles," that is, to build a (mental) model that explains a phenomenon in terms of elementary events. In such instances, analogical reasoning is a fast and appropriate approach to problem solving.

\section{Creating}

The last marketing problem-solving mode that we distinguish is creating. Using the creating mode, a marketing decision maker searches for novel concepts, solutions, or ideas in responding to a situation that has not occurred before. However, what precisely is a creative idea, and how do marketers hit upon those ideas that really make a difference in the marketplace? What was the creative process that led to successes such as Post-it, the famous yellow pieces of paper from $3 \mathrm{M}$, or the catchy brand name Q8, of Kuwait Petroleum?

It is widely accepted that marketing requires a good deal of creativity. Marketing problems are often not well-defined in terms of goals, means, mechanisms, and constraints and often do not lend themselves to the procedural or logical reasoning used in conventional computer programs or knowledge-based systems. The cognitive model of a marketer following the creating mode is one of a decision maker whoconsciously or unconsciously, by means of mapping, exploring, and transforming conceptual space; expanding the number of possible solutions through divergent thinking; and making connections and associations - is searching for novel and effective ideas and solutions to strengthen the market position of the product, brand, or company. Creating can refer to all aspects of the marketing management domain, including generating ideas for new products or services, innovative advertising or sales promotion campaigns, new forms of distribution, and ingenious pricing. Creativity is an important asset. Many companies owe their existence to a creative new product or process, and creativity is often the means for survival as well as growth.

In Figure 31.2, we summarize the most important decision situation characteristics that will be associated with the use of a specific marketing problem-solving mode.

\section{Marketing Management \\ SUPPORT SYSTEMS}

In the introduction, we have been talking about MMSSs without providing a clear definition or description. We will do so now. We define a marketing management support system (MMSS) as follows:

Any device combining (a) information technology, (b) analytical capabilities, (c) marketing data, and (d) marketing knowledge, made available to one or more marketing decision maker(s) to improve the quality of marketing management.

The term marketing management support systems is a collective noun for a variety of systems that have been developed since the early 1960s. We distinguish two broader categories of MMSS: data-driven MMSS and knowledgedriven MMSS. Data-driven MMSSs process and manipulate quantitative marketing data through the use of mathematical and statistical methods. In the mid-1980s, a new generation of MMSSs was developed. These systems emphasized the marketing knowledge rather than quantitative data. Knowledge-driven MMSSs process (qualitative) marketing knowledge using techniques developed in artificial intelligence.

\section{Data-Driven Marketing Management Support Systems}

\section{Marketing Models}

These systems mark the start of the use of computers to aid marketing decision making; they consist of mathematical representations of 


\begin{tabular}{|c|c|c|c|c|}
\hline \multirow[b]{2}{*}{ Antecedents } & \multicolumn{4}{|c|}{ MARKETING PROBLEM-SOLVING MODES } \\
\hline & Optimizing & Reasoning & Analogizing & Creating \\
\hline $\begin{array}{l}\text { Problem } \\
\text { characteristics }\end{array}$ & $\begin{array}{l}\text { - High } \\
\text { structuredness } \\
\text { - Precise knowledge } \\
\text { of relationships } \\
\text { - Quantitative data }\end{array}$ & $\begin{array}{l}\text { - Moderate } \\
\text { structuredness } \\
\text { - Knowledge of } \\
\text { most important } \\
\text { variables } \\
\text { - Quantitative or } \\
\text { qualitative data }\end{array}$ & $\begin{array}{l}\text { - Low } \\
\text { structuredness } \\
\text { - Weak theory } \\
\text { - Experiences } \\
\text { and/or cases }\end{array}$ & $\begin{array}{l}\text { No precise } \\
\text { problem } \\
\text { formulation } \\
\text { - No theory } \\
\text { - Remote } \\
\text { associations }\end{array}$ \\
\hline $\begin{array}{l}\text { Decision } \\
\text { environment } \\
\text { characteristics }\end{array}$ & $\begin{array}{l}\text { - Ample time frame } \\
\text { - Stable market } \\
\text { - Quantitative/ } \\
\text { analytical attitude } \\
\text { in company }\end{array}$ & $\begin{array}{l}\text { - Limited time } \\
\text { frame } \\
\text { - Dynamic market } \\
\text { - Analytical attitude } \\
\text { in company }\end{array}$ & $\begin{array}{l}\text { - Little time } \\
\text { available } \\
\text { - Stable market } \\
\text { - Heuristic/holistic } \\
\text { attitude in } \\
\text { company }\end{array}$ & $\begin{array}{l}\text { - No time pressure } \\
\text { - Dynamic market } \\
\text { - Heuristic/holistic } \\
\text { attitude in } \\
\text { company }\end{array}$ \\
\hline $\begin{array}{l}\text { Decision maker } \\
\text { characteristics }\end{array}$ & $\begin{array}{l}\text { - Analytical } \\
\text { cognitive style } \\
\text { - Experience varies } \\
\text { - Academic } \\
\text { education } \\
\text { - Quantitative skills }\end{array}$ & $\begin{array}{l}\text { - Analytical } \\
\text { cognitive style } \\
\text { - Experienced } \\
\text { decision maker } \\
\text { - Academic } \\
\text { education } \\
\text { - Quantitative skills }\end{array}$ & $\begin{array}{l}\text { - Heuristic } \\
\text { cognitive style } \\
\text { - Experienced } \\
\text { decision maker } \\
\text { - Professional } \\
\text { education } \\
\text { - Limited } \\
\text { quantitative skills }\end{array}$ & $\begin{array}{l}\text { - Heuristic cognitive } \\
\text { style } \\
\text { - Experience varies } \\
\text { - No specific } \\
\text { education } \\
\text { - Creative skills } \\
\text { and intrinsic } \\
\text { motivation }\end{array}$ \\
\hline
\end{tabular}

Figure 31.2 Marketing Problem-Solving Modes and Their Antecedents

marketing problems that aim at finding optimal values for marketing instruments. The philosophy underlying these systems is that it is possible to find an objective best solution. Marketing models signify the start of the use of computers for marketing decision making (Bass et al., 1961; Buzzell, 1964; Frank, Kuehn, \& Massy, 1962). This work in the early 1960 s was the beginning of a model-building tradition in marketing that continues through today. Developments in the fields of operations research/management science and econometrics led to the start of marketing modeling. The field of operations research/management science (OR/MS) emerged during World War II and focused first on problems in production, operations, and logistics. Because of the successes achieved in these areas, the practitioners in this field attempted to tackle problems in other areas. The OR/MS approach entered marketing in the early 1960s (Eliashberg \& Lilien, 1993). Several types of models have been developed since then (Lilien, Kotler, \& Moorthy, 1992). When we talk about marketing models in this chapter, we specifically mean prescriptive (or normative) models, those that aim at finding an optimal solution. In terms of the ORAC model, marketing models follow an optimizing mode.

Over the years, especially in the 1970s and 1980s, a large collection of marketing models have been developed. These models support decisions on a variety of marketing variables. Among the most prominent were models such as MEDIAC (Little \& Lodish, 1969), SPRINTER (Urban, 1970), CALLPLAN (Lodish, 1971), DETAILER (Montgomery, Silk, \& Zaragoza, 1971), ADMOD (Aaker, 1975), STRATPORT, and SH.A.R.P. (Bultez \& Naert, 1988).

Recently, a new type of optimization models in marketing has come to prominence in the area of CRM. Models that calculate the probability that a customer or prospect will respond to an offer are used to optimally allocate marketing expenditures over customers/prospects (Reinartz \& Kumar, 2000, 2003).

For a more extensive discussion of marketing models, we refer to the contribution of Lilien and Rangaswamy (Chapter 12) in this handbook. 


\section{Marketing Information Systems}

From the mid-1960s onward, marketers could make use of marketing information systems (MKIS) for the storage, retrieval, and (statistical) analysis of data. At the time that the concept of marketing information systems was introduced, businesses were caught in an "ironic dilemma" (Brien \& Stafford, 1968). Enormous amounts of data were generated (already then), the sheer volume of which appeared to increase exponentially. Despite this abundance of information, managers complained that they had insufficient, inappropriate, or untimely information to support their decision making. The process of developing timely, pertinent decision data for marketing management was characterized as the function of an MKIS rather than simply marketing research.

The importance of marketing information increased as companies grew larger and became more complex and marketers got further removed from firsthand contact with the "scenes of marketing action" (Kotler, 1966). Marketers increasingly had to rely on secondhand information to get a picture of what was happening in the market. According to Kotler (1966), this information suffered from a number of problems. Too much information of the wrong kind was available, while not enough of the right kind was. This, in the view of Kotler, led key executives to be often ignorant of important marketing developments. They did not optimally use the existing information and tended to distort information in passing it on.

Kotler (1966) called for a systematic solution in order to let executives make effective marketing decisions in an age characterized by intensifying competition, frequent product changes, and shifting consumer wants. ${ }^{2}$ At the time of the introduction of the concept of marketing information systems, marketing research tended to be rather unsystematic, emphasizing data collection per se rather than the development of useful information for the support of marketing decision making.

By means of manipulating quantitative information, marketing information systems assist marketers in analyzing what has happened in the market and determining possible causes of events. The first marketing information systems were mainly a combination of marketing data and information technology, that is, systems with an emphasis on data storage and retrieval. Later, statistical procedures (analytical capabilities) were added. Nowadays, many MMSSs in companies are de facto marketing information systems. The main function of an MKIS is to provide information (predominantly quantitative) about what is going on in the market, that is, to answer the question, "What happened?" MKISs are basically passive systems. They provide information. However, it is up to the marketing decision maker to attach conclusions to this information and to decide whether to act on those conclusions. Although only limited attention has been paid to marketing information systems in the academic literature, in companies, they are much more prominent than marketing models. Most of the CRM systems that are used in practice nowadays can also be classified as marketing information systems.

\section{Marketing Decision Support Systems}

Whereas marketing information systems are relatively passive systems that provide marketers only with the information they are looking for, marketing decision support systems are more active. Marketing decision support systems (MDSSs) represent the more general concept of decision support systems (DSSs) in the field of marketing. Little (1979) defines a marketing decision support system as "a coordinated collection of data, models, analytical tools and computing power by which an organization gathers information from the environment and turns it into a basis for action" (p. 9). An MDSS makes it possible for marketing managers to model marketing phenomena according to their own ideas (mental models). In that sense, a marketing decision support system can be conceived of as a "relaxed" version of the more rigorous marketing models. On the other hand, an MDSS can also be seen as an extension of a marketing information system. Like an MKIS, an MDSS consists of a combination of information technology, marketing data, and analytical capabilities but with much more emphasis on the last component. An MDSS contains an explicit model base. Whereas an MKIS is particularly geared toward answering "what" questions (What is happening in the market?) 
and "why" questions (Why did it happen?), an MDSS is especially equipped to answer "whatif" questions (What will happen if?). Taking advantage of its model base, the user of an MDSS can carry out simulations to answer such questions. The type of models in MDSS will be of a predictive rather than a normative nature.

Examples of marketing decision support systems described in the marketing literature are the ADBUDG system (Little, 1970), which predicts market shares for given advertising budgets (an MDSS “avant-la-lettre"), and ASSESSOR (Silk \& Urban, 1978), which predicts the market share of a new product given its attributes and the introduction campaign. Other well-known MDSSs are systems such as BRANDAID (Little, 1975a, 1975b) and SCAN*PRO (Wittink, Addona, Hawkes, \& Porter, 1988). SCAN*PRO, which estimates promotional effects based on Nielsen's SCANTRACK data, aims at providing brand managers with an understanding of the impact of promotional activities. Alternative sales promotion programs can be compared in terms of their impact on sales. The system has been very successful and has been used by ACNielsen in more than a thousand applications.

\section{Knowledge-Driven Marketing Management Support Systems}

\section{Marketing Expert Systems}

The basic philosophy underlying expert systems is to capture the knowledge from an expert in a specific domain and make that knowledge available in a computer program for solving problems in that domain. The goal of an expert system is to replicate the performance levels of (a) human expert(s) in a computer model (Rangaswamy, 1993). These systems take a normative approach in searching for the best solution to a given problem. With marketing expert systems (MESs), we primarily refer to systems that use rule-based knowledge representation and reasoning (see Wierenga \& Van Bruggen, 2000, chap. 5).

Sales promotion is the marketing domain for which the largest number of marketing expert systems has been developed. MESs support such sales promotion tasks as the following: evaluating the effect of sales promotions, finding the right type of sales promotion given the position of the brand and the management objectives, spotting competing promotions, and designing weekly newspaper advertisements for promoted products. Marketing expert systems that support monitoring markets also occur with a relatively high frequency. Especially because of the "scanning revolution," marketing decision makers are swamped with data and need support for finding the "news" in these large quantities of tables and numbers. CoverStory and its successor, SalesPartner (Schmitz, 1994), do exactly that. Other domains for which expert systems have been developed are advertising and media planning.

Expert systems are most suitable to the more operational type of marketing problems, the type of task that a marketing decision maker would delegate to someone else. The suitability of expert systems is thus restricted to a particular subset of all marketing problems: those that are relatively structured and primarily diagnosing/ monitoring in character. Problems with evident managerial and strategic dimensions would not easily be entrusted to an expert system. Expert systems reflect the more repetitive and mechanical aspects of the data analyst's task. So, expert systems will not replace marketing managers. However, for specific tasks that are relatively structured and repetitive and for which agreement exists about how they should be dealt with, expert systems can produce important efficiency gains. An example is scanning data, where huge amounts of data can be monitored and diagnosed by means of expert system technology in a very short time.

\section{Marketing Knowledge-Based Systems}

These systems were introduced in the early 1990s and form a broader class of systems than marketing expert systems. They obtain their knowledge from any source, not just from human experts but also from textbooks, cases, and so on. Furthermore, knowledge can be represented in multiple forms, that is, not only by means of rules, as in expert systems, but also, for example, by means of semantic networks and frame-based hierarchies. Unlike marketing expert systems, marketing knowledge-based systems do not focus on finding a best solution but emphasize the reasoning processes of decision makers. 
An example of a marketing knowledge-based system using an object-oriented design is Brand Manager's Assistant (McCann, Lahti, \& Hill, 1991), which supports brand managers by monitoring, analyzing, and designing tasks related to their brands. Increasingly, knowledge systems make use of "hybrid environments" in which multiple representation paradigms are combined into a single integrated programming environment. Rules and frame-/object-based representations can, for example, be combined to benefit from the relative advantages of both approaches. An example of a comprehensive MKBS is BRANDFRAME, a system designed to support decision making by brand/product managers in the fast-moving consumer products industry (Wierenga \& Van Bruggen, 2001).

\section{Marketing Case-Based Reasoning Systems}

This third type of knowledge-driven MMSS first appeared in the mid-1990s. These systems focus on the support of reasoning by analogies. Marketing case-based reasoning systems make cases available in a case library and provide tools for accessing them. The heart of a case-based reasoning system is the database of earlier cases, the so-called case base. Cases are stored with as much relevant information as possible (referring to the problem, the solution, and the outcome, respectively). When a new problem arises, the system searches for a problem that is as similar as possible to the new one (according to some specified criteria) and presents the solution for that problem as a suggested ("ballpark") solution for the new problem. An adaptation may be necessary to derive a solution for the new situation from the "old" solution. This solution may then be implemented and, subsequently, retained in the case base as an additional case or a revision of the original case. A case-based reasoning system not only contains cases (contextual pieces of knowledge) but can also include a certain amount of general knowledge. Such general knowledge concerns the way that a comparison between the new problem and the cases in the case base can be made, how similar cases can be efficiently found in the case base, and how the adaptation strategies can be applied.

Burke's (1991) ADDUCE system uses analogical reasoning for predicting how consumers will react to new advertisements by searching for relevant past advertising experiments and generalizing the results across similar contexts. McIntyre, Achabal, and Miller (1993) developed a system that uses case-based reasoning to forecast the sales generated by sales promotions in a retailing environment. Althuizen and Wierenga (2005) use case-based reasoning for the design of sales promotion campaigns.

\section{Marketing Neural Networks}

These systems model the way human beings attach meaning to a set of incoming stimuli, that is, how people recognize patterns from signals. They were inspired by the actual physical process that takes place in the human brain, where incoming signals are transmitted through a massive network of connections formed by links among neurons in the brain. Through this process, a human being is able to recognize patterns in sets of incoming stimuli; that is, a specific output is connected to input.

One can question in what respect(s) people are smarter than computers. Human beings are not as good as computers at performing complex computations (number crunching) or at thoroughly and consistently searching through large databases. However, people perform much better than computers at tasks such as recognition (e.g., a face, a situation) and making associations (e.g., solving cryptograms). People are not only extremely fast at such tasks but also very robust. Frequently, objects and events do not appear complete and in full clarity. Often, they are only partly visible, distorted, blurred, and messy. Nevertheless, in many cases, human beings are still able to recognize them and (re)act in an adequate manner. Experience and expertise, to an important degree, are based on pattern recognition. An experienced marketer, when exposed to a complex marketing situation, often immediately comes up with a correct diagnosis or with a plan for action. Sometimes this is called "solving by intuition," but according to Simon (1995), a better label would be "solving by recognition." Somehow, the manager recognizes something in the situation that triggers a reaction.

In data-rich environments (such as marketing), it is important to equip computers with such pattern recognition capabilities. Suppose that a 
company has a database describing a large number of past introductions of new products. For each introduction, a record is available that describes the product introduction (characteristics of the new product, the market, the competitors, data about the introduction campaign, and so on). Furthermore, the record contains information about whether the new product became a success $(\mathrm{S})$ or a failure $(\mathrm{F})$. An experienced marketer would learn from earlier product introductions, and this education would help him or her to predict the success of a new introduction. We can train an (artificial) neural network to do exactly the same things. Such a network would be shown, for a series of new product introductions, the data on the characteristics of the product introduction and the corresponding success/failure outcome. The product introduction characteristics would be the input of the network, the outcome (success or failure) would be the output, and the network would train the associations between input and output patterns. After this training, the network would be able to classify other new product introductions (not used during the training) as successes or failures. Such a trained network could then be used to assist managers in judging new product proposals.

\section{Marketing Creativity Support Systems}

Marketing creativity support systems are computer programs that stimulate and endorse the creativity of marketing decision makers. Although the number of creativity enhancement programs developed so far is limited, we expect these systems to become more popular in the coming years, given the increasing importance of creativity in marketing - for example, in the development of new products. Although marketing has applied techniques for stimulating the creativity of decision makers for a long time (brainstorming, lateral thinking, morphological analysis, etc.; see Crawford, 1997), these methods operated without computers.

The work on creativity support systems has emerged in the general area of information systems/decision support systems. An example of a creativity support system that was specifically designed for marketing purposes is the Computer-Aided Advertising System (CAAS). CAAS was developed at the University of
Saarbrucken by Kroeber-Riel and his coworkers (Esch \& Kroeber-Riel, 1994; Kroeber-Riel, 1993). The purpose of CAAS is to support the development and diagnosis of advertisements. It consists of several modules, of which the so-called Search System supports the creative process of generating visual ideas, persuasive motives, or pictures and ideas for effective pictorial execution (Kroeber-Riel, 1993).

In Figure 31.3, we summarize the most important characteristics of the different types of MMSSs currently available.

\section{TOWARD THE SUCCESSFUL \\ IMPLEMENTATION OF MARKETING Management Support Systems}

So far, we have described the various ways marketing decision makers solve marketing problems (i.e., the four marketing problemsolving modes) and the various MMSSs that can support the marketer. We propose that the specific characteristics of the decision situation will determine which marketing problem-solving mode will (most likely) be used. Next, the marketing problem-solving mode that is being used will determine which MMSS is most appropriate and most likely to be successful. The relationship between the decision situation and MMSS is shown graphically in Figure 31.4.

We now link each of the four marketing problem-solving modes to specific MMSSs. For the design and implementation of management support systems, Dutta, Wierenga, and Dalebout (1997b) delineate two important dimensions: the object of support and the mode of support.

\section{Object of Support}

Three different objects of support can be distinguished: the outcome, the process, and learning. The outcome-oriented view of decision support is primarily concerned with the final decision. The emphasis is on ensuring that the best or "correct" output is produced for the appropriate set of inputs. This is a matter of finding the most efficient computation algorithm. However, for many problems, there does not exist a best solution in an objective sense. In these cases, the decision process can be taken as the object of support. The 


\begin{tabular}{|c|c|}
\hline Type of MMSS & Characterizing Keywords \\
\hline Marketing Models (MM) & $\begin{array}{l}\text { - Mathematical representation } \\
\text { - Optimal values for marketing instruments } \\
\text { - Objective } \\
\text { - Best solution }\end{array}$ \\
\hline Marketing Information Systems (MKIS) & $\begin{array}{l}\text { - Storage and retrieval of data } \\
\text { - Quantitative information } \\
\text { - Registration of "what happens in the market" } \\
\text { - Passive systems }\end{array}$ \\
\hline Marketing Decision Support Systems (MDSS) & $\begin{array}{l}\text { - Flexible systems } \\
\text { - Recognition of managerial judgment } \\
\text { - Able to answer "why" questions (analysis) and } \\
\text { "what-if" questions (simulation) }\end{array}$ \\
\hline Marketing Expert Systems (MES) & $\begin{array}{l}\text { - Centers on marketing knowledge } \\
\text { - Human experts } \\
\text { - Rule-based knowledge representation } \\
\text { - Normative approach: best solution }\end{array}$ \\
\hline Marketing Knowledge-Based Systems (MKBS) & $\begin{array}{l}\text { - Diversity of methods, incuding hybrid approaches } \\
\text { - Structured knowledge representation, including } \\
\text { frame-based hierarchies } \\
\text { - Model-based reasoning }\end{array}$ \\
\hline $\begin{array}{l}\text { Marketing Case-Based Reasoning } \\
\text { Systems (MCBR) }\end{array}$ & $\begin{array}{l}\text { - Similarity with earlier cases } \\
\text { - Storage of cases in memory } \\
\text { - Retrieval and adaptation } \\
\text { - No generalization }\end{array}$ \\
\hline Marketing Neural Networks (MNN) & $\begin{array}{l}\text { - Training of associations } \\
\text { - Pattern recognition } \\
\text { - No a priori theory } \\
\text { - Learning }\end{array}$ \\
\hline Marketing Creativity Support Systems (MCSS) & $\begin{array}{l}\text { - Association through connections } \\
\text { - Idea generation } \\
\text { - Endorse creativity in problem solving }\end{array}$ \\
\hline
\end{tabular}

Figure 31.3 Characteristics of Marketing Management Support Systems

process-oriented view of decision support focuses not on the final outcome but on the process by which decisions are made. In this situation, a support system is conceived of as an intervention in the decision process that should increase the quality of this process. A process-oriented approach to decision support is especially relevant when there is uncertainty in the environment and when the problem is not very well structured. Finally, when learning is the object of decision support, the relevant question is how to improve the decision and the decision process. The ability to question decision procedures and to adopt new, innovative ones is a critical component of a decision maker's learning capabilities.

\section{Mode of Support}

Three different modes of decision support can be distinguished: automating, informating, and stimulating. Automation of decision making has been the traditional strength of operations research/management science approaches. Management support systems that emphasize automation have certain decision procedures and mechanisms hardwired into the system as optimization procedures. Zuboff (1985) first used the term informate to denote the capability of intelligent technology to capture and provide information. Zuboff referred primarily to the informatization capabilities of large databases. 


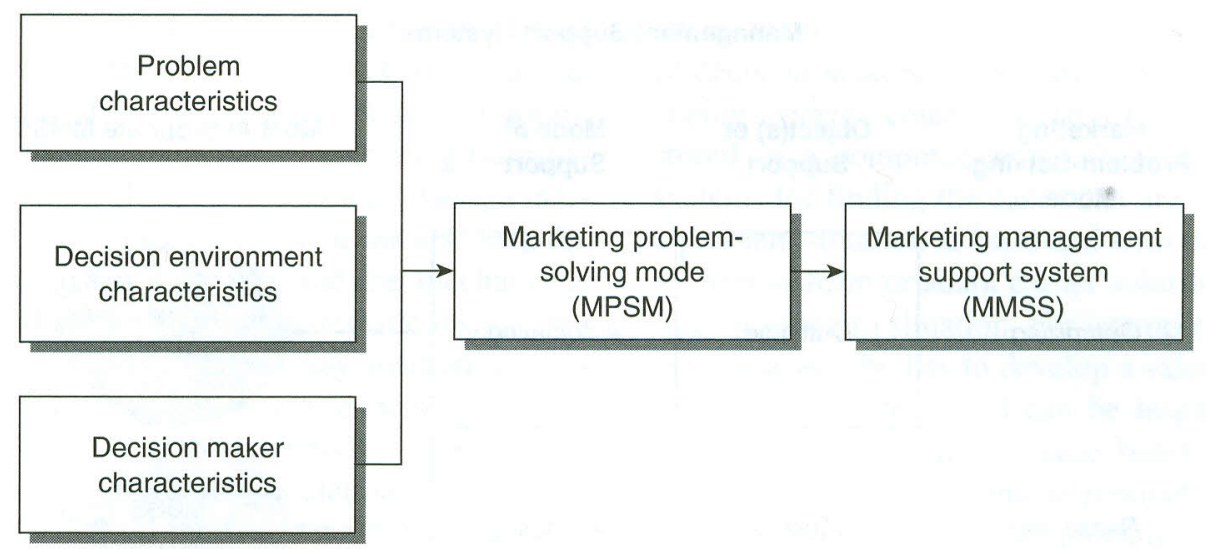

Figure 31.4 From Decision Situation to Marketing Management Support System

Informating has a more active connotation than informing: The attention of the decision maker is drawn to specific events. Finally, in the stimulating mode of decision support, the system aids the decision maker in finding new solutions by questioning existing frames and norms, noticing special features in the decision environment, making (remote) associations, and so on.

There are "dominant matches" between the objects and modes of decision support (Dutta et al., 1997b). These dominant matches can be related to the three types of management support system characteristics identified by Silver (1991). These characteristics are restrictedness, guidance, and customizability. If the object is to support the outcome of a decision, the dominant match is with the automating mode. This leads to restrictive systems that are prescriptive and normative in nature. Many of the traditional management support systems fall into this category. If the object of support is the decision process, the decision support should have a guidance role, which is offered by the decision support mode informating. The learning view of decision support calls for greater emphasis on stimulation. It is important that support systems stimulate decision makers to use exploratory modes of problem solving. The support system should continuously be adapted to the changing needs of the environment. In such a situation, the system should have a high degree of customizability: Decision makers should have a lot of leeway in choosing how to apply the system.
When we apply the design dimensions object of support and mode of support to the ORAC classification, we arrive at a mapping of marketing problem-solving modes and the most appropriate type of MMSS(s), as given in Figure 31.5 (adapted from Wierenga \& Van Bruggen, 1997).

\section{Optimizing Support}

In the case of optimizing, a best solution exists, and the MMSS should ensure that this solution is found. So the emphasis is on the final solution, that is, the outcome of the decision process. In principle, decisions can be automated and left to a computer. In this situation, there is typically a high degree of structure and little uncertainty in the decision problem, and users can have low domain skills. Typical examples of marketing problems that can be approached in this way are media allocation, shelf-space allocation, sales force planning, and the selection of target prospects for direct marketing campaigns.

The first type of MMSS that became available to match the design requirements of the optimizing mode were marketing models. Given the input data (objectives, resources, etc.), the algorithm produces a solution like the best media plan, the optimal shelf-space allocation in a supermarket, or the optimal sales-call schedule. The solution of the problem 
Management Support Systems

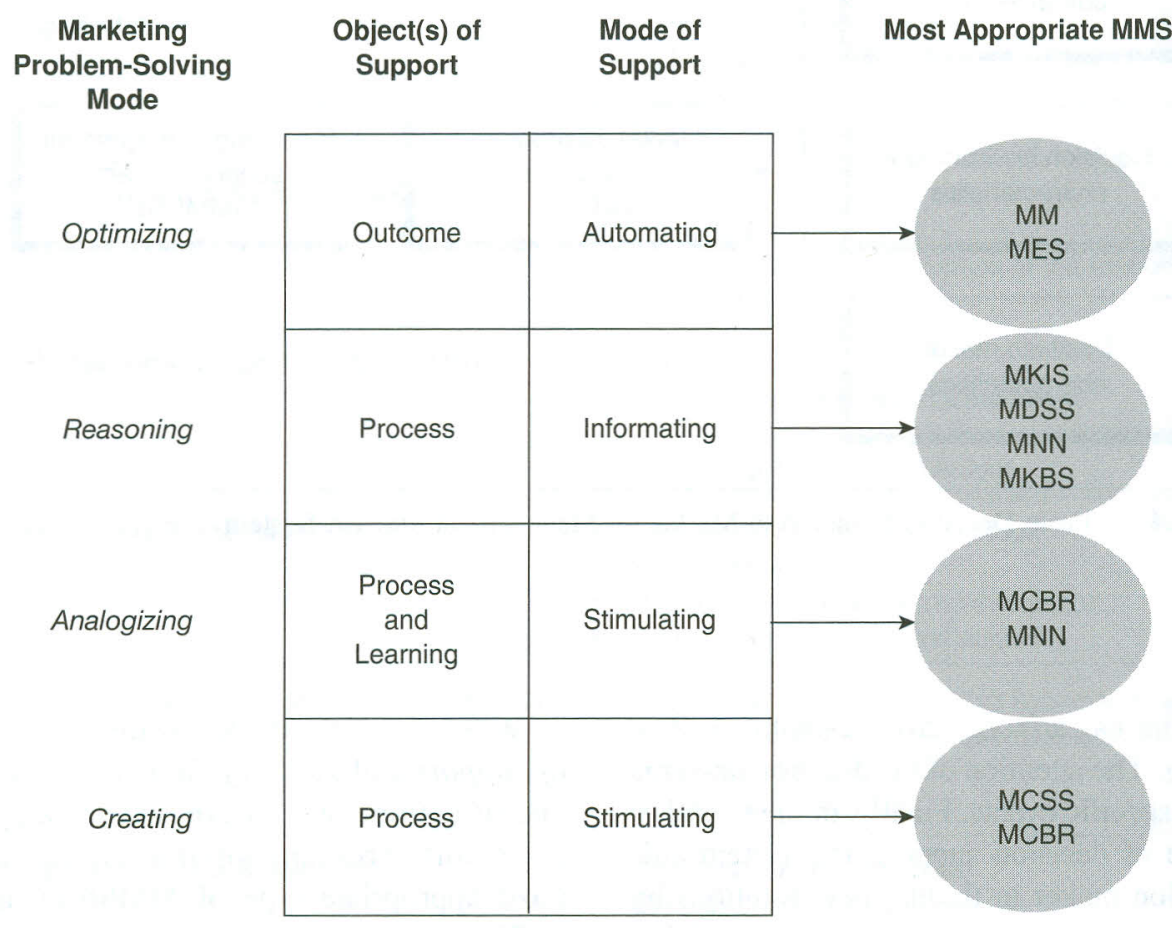

Figure 31.5 Mapping Marketing Problem-Solving Modes and Marketing Management Support Systems

can be delegated to a relatively low-skilled employee who need not have a lot of marketing expertise. Whereas marketing models provide the best quantitative solution, marketing expert systems aim at providing the best solution if the problem is described in terms of qualitative relationships between the variables. Under the optimizing mode, a marketing model might be used to determine the advertising budget, and a marketing expert system might subsequently be used to find out what the copy should be and what the execution of the advertisements should look like. Everyone familiar with marketing decision making will recognize that solving a marketing problem purely by optimizing is rare. Elements of managerial judgment, which cannot be put intơ a computer system, practically always come into play in marketing. Often, however, parts of a marketing problem can be defined as structured subproblems that are amenable to optimization by means of models or expert systems.

\section{Reasoning Support}

The reasoning mode takes the mental model of the decision maker as its starting point. No objective true representation of the decision situation exists. Ultimately, the final decision will be the result of a process in the decision maker's mind. Therefore, in the reasoning mode, the object of support for the decision maker should not be a particular outcome (a precise recommendation on what to do) but rather the marketing manager's decision-making process. The basic mode of support in this situation is informating. Under the reasoning mode, an MMSS should provide information about what is going on in the market and actively draw a manager's attention to significant events. MMSSs can support the reasoning mode in two different ways:

1. By supporting the formation and maintenance of mental models of managers

2. By reasoning with these mental models 
In the first option, information is needed about what happens in the market, that is, actual facts and data (answering the "what" question). This is the main function of marketing information systems. Because of its model base, a marketing decision support system can also help the decision maker to understand the mechanisms in a market by providing systematic insight into the relationships between key marketing variables, such as advertising expenditures and brand awareness or advertising expenditures and sales. By means of simulation (i.e., answering "what-if" questions), a marketer can use a marketing decision support system to explore the consequences of alternative marketing strategies. Marketing neural networks can also help to explore what is going on in a market. A marketing neural network can discover patterns in the interdependencies between marketing variables. For example, it can capture the characteristics that distinguish successful new products from unsuccessful ones.

In the second option, it is necessary to represent a decision maker's mental model in a computer and reason with this model. A marketing knowledge-based system is particularly suited for this purpose. Systems can be built for monitoring and diagnosing market events and suggesting appropriate actions in the same way as the manager would do. An example of such a system is CoverStory (Schmitz, 1994; Schmitz, Armstrong, \& Little, 1990).

\section{Analogizing Support}

In the analogizing mode, the decision maker uses solutions from earlier, similar decision situations to develop a decision for a current problem. In the analogizing mode, therefore, the primary object of support is the process of finding suitable cases and adapting them for the current problem situation. In the analogizing mode, the MMSS should stimulate the decision maker by actively coming up with solutions of earlier cases and proposing transformations of these solutions to adapt them to the current problem situation. Learning will take place so that future decisions can benefit from current experiences. Marketing case-based reasoning systems are the type of MMSS that match the requirements of the analogizing mode. The development of casebased reasoning technology was inspired by the desire to support the analogy-seeking behavior of decision makers. As we saw, case-based reasoning systems consist of (large) sets of cases stored in a computer, with efficient indexing systems for finding the cases that are similar to a problem situation at hand and with the capacity to transform or adapt earlier solutions to the current problem situation. For example, a product manager who has to develop a sales promotion for his or her brand can be inspired by a campaign (present in the case base) that has been successful for a similar product in a different market. Or the sales potential of a new outlet of a service company in a city not yet covered may be estimated on the basis of the sales figures of existing outlets in cities that are comparable in terms of size, customers, and the competition. The strength of a computerized case-based reasoning system is that it augments a decision maker's memory by providing access to a large collection of relevant cases. Human decision makers are fairly good at adapting these cases to the situation at hand (Dutta, Wierenga, \& Dalebout, 1997a). Ultimately, in the analogizing mode, as the number of cases in the case base grows larger, some form of generalization takes place (learning from experience). For that purpose, marketing neural networks might be used here also, in order to search for patterns in the cases of the case base.

\section{Creativity Support}

In the creating mode, the marketing decision maker searches for concepts, solutions, or ideas that are novel, often in response to a situation that has not occurred before. Here an MMSS should support the creative process and should fulfill a stimulating role, that is, generate cues and ideas that trigger the user. Marketing creativity support systems (MCSSs) can be used for this purpose. However, it has been demonstrated that the analogical reasoning that is involved in case-based reasoning can also be conducive to creative "leaps" (Holyak \& Thagard, 1995). Therefore, marketing casebased reasoning systems (MCBRs) can also provide creativity support.

In our approach, we thus transform decision situations, via marketing problem-solving modes, into requirements for decision support. By doing so, one can determine the MMSS that 
Management Support Systems

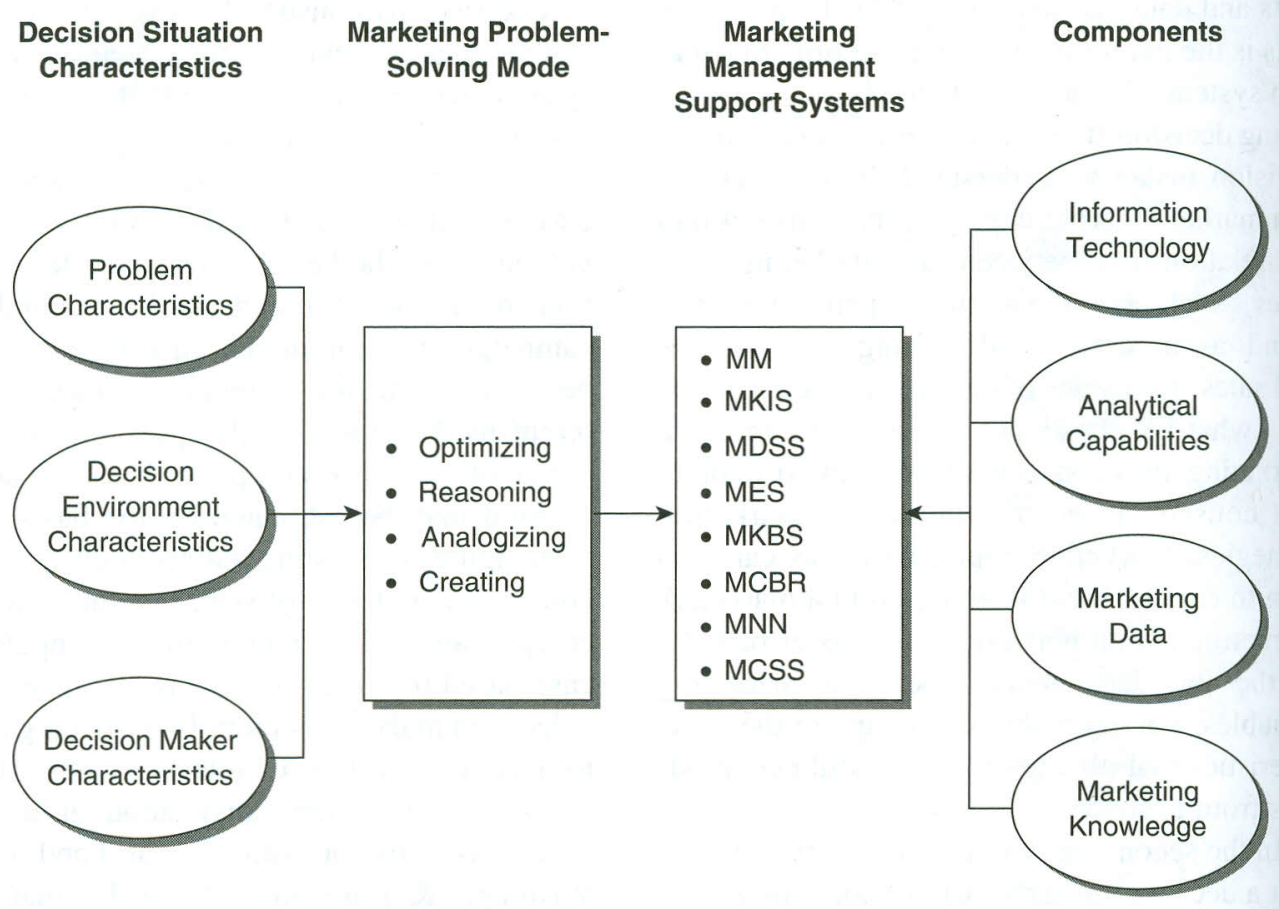

Figure 31.6 Linking Marketing Problem-Solving Modes and Marketing Management Support Systems

fits best with the decision situation. The complete mapping of decision situation characteristics and MMSS is shown in the integrating framework of Figure 31.6.

This framework encompasses the complete stretch between, on one hand, the characteristics of the decision situation (left side of the figure) and, on the other hand, the components that constitute MMSSs (the right side of the figure). The decision situation characteristics are translated into marketing problem-solving modes and the constituting components into MMSSs. The heart of the framework is the centrepiece of successful support: the fit between MPSM and MMSS.

The frameworks in Figure 31.5 and Figure 31.6 describe which specific type of MMSS is most appropriate for a given decision situation. This framework can also be used to determine what type of decision support system is most appropriate for a particular marketing decision maker. For example, a decision maker who deals with structured problems and well-known relationships between the relevant variables (e.g., a media planner) is best supported with marketing models and expert systems (i.e., supporting the optimizing mode). However, a new business manager in an IT company operates in a lowly structured environment, with little hard knowledge and a dynamic environment. In such a situation, decision support should be more directed toward systems that help analogical thinking and creativity.

\section{A Model for the Successful IMPLEMENTATION OF MARKETING Management Support Systems}

A good match between demand and supply of decision support is a necessary but not always sufficient condition for the successful implementation of MMSSs in organizations. In this section, we will describe our model that specifies the antecedents of the successful implementation and use of MMSSs in organizations. We distinguish five main factors that determine the success of MMSSs in organizations. These are (1) the demand for decision support (the 
characteristics of the decision situation), (2) the supply of decision support (the decision support offered by the MMSS), (3) the match between demand and supply, (4) the design characteristics of the particular system, and (5) the characteristics of the implementation of the particular system. Together with (6), the dependent variable "success of the MMSS," these five factors constitute the main building blocks of the framework presented in Figure 31.7.

We propose that the primary determinant of the success of an MMSS is the match between the demand side (the MPSMs to be supported) and the supply side (the functionality of the MMSSs employed). We distinguish between the potential success of an MMSS and its actual success. We think that the match between demand and supply determines the potential success of an MMSS. To what extent this success will be realized depends on the design characteristics of the MMSS and the characteristics of its implementation.

\section{The Match Between Demand and Supply}

Which MMSS is most suitable depends on the match between demand and supply. As early as 1967, Cox and Good mentioned the "systemmanager balance" as an important element of marketing information systems. More recently, the concept of task-technology fit was introduced by Goodhue and Thompson (1995). The match between the demand and supply sides of decision support (Block 3 in Figure 31.7) is the central element in our framework of the factors that drive the success of MMSS. We now discuss the other factors.

\section{Design Characteristics of Marketing Management Support Systems}

Two different systems for media planning may both take an optimization approach, but one system may require the input of a lot of technical parameters, whereas the other system may receive its input through a user-friendly dialogue. In such a case, the chance of success of the more user-friendly design is much higher. The effect of design and implementation characteristics on the success of a system has been studied extensively in the general
DSS/information systems (IS) field. Papers that have studied the effects of design and implementation characteristics for marketing management support systems (e.g., Wierenga \& Oude Ophuis, 1997; Zinkhan, Joachimsthaler, \& Kinnear, 1987) tend to find effects that are similar to those found in the general DSS/IS field. The most important design characteristics of MMSSs are accessibility, system integration, adaptability, presentation of output, user interface, system quality, and information quality.

\section{Characteristics of the Implementation Process}

Characteristics of the implementation process have been a longstanding concern for both decision support systems (Schultz \& Slevin, 1972) and marketing models (Naert \& Leeflang, 1978). The most important implementation characteristics are user involvement, top management support, communication about the MMSS, marketing orientation, presence of an MMSS champion, attitude of the IS department, in-company developed versus purchased, and training of the users.

\section{Success Measures for Marketing Management Support Systems}

There are different ways to measure the success of an MMSS. From the start of DSS/IS research, the question of what the dependent variable should be has occupied an important place in the literature (DeLone \& McLean, 1992; Ives \& Olson, 1984; Keen, 1980; Zmud, 1979). So far, this debate has not led to the adoption of one IS success measure. DeLone and McLean (1992), who examined dependent variables in 100 empirical DSS/IS studies, concluded that "there are nearly as many measures as there are studies" (p. 61). The most important success measures for MMSS are technical validity, adoption and use, user impact variables, and organizational impact variables.

Technical validity - that is, the extent to which the MMSS is a valid representation of the marketing processes and makes (statistically) accurate predictions - is a necessary condition for the success of an MMSS. However, it is not a sufficient condition since even the most 


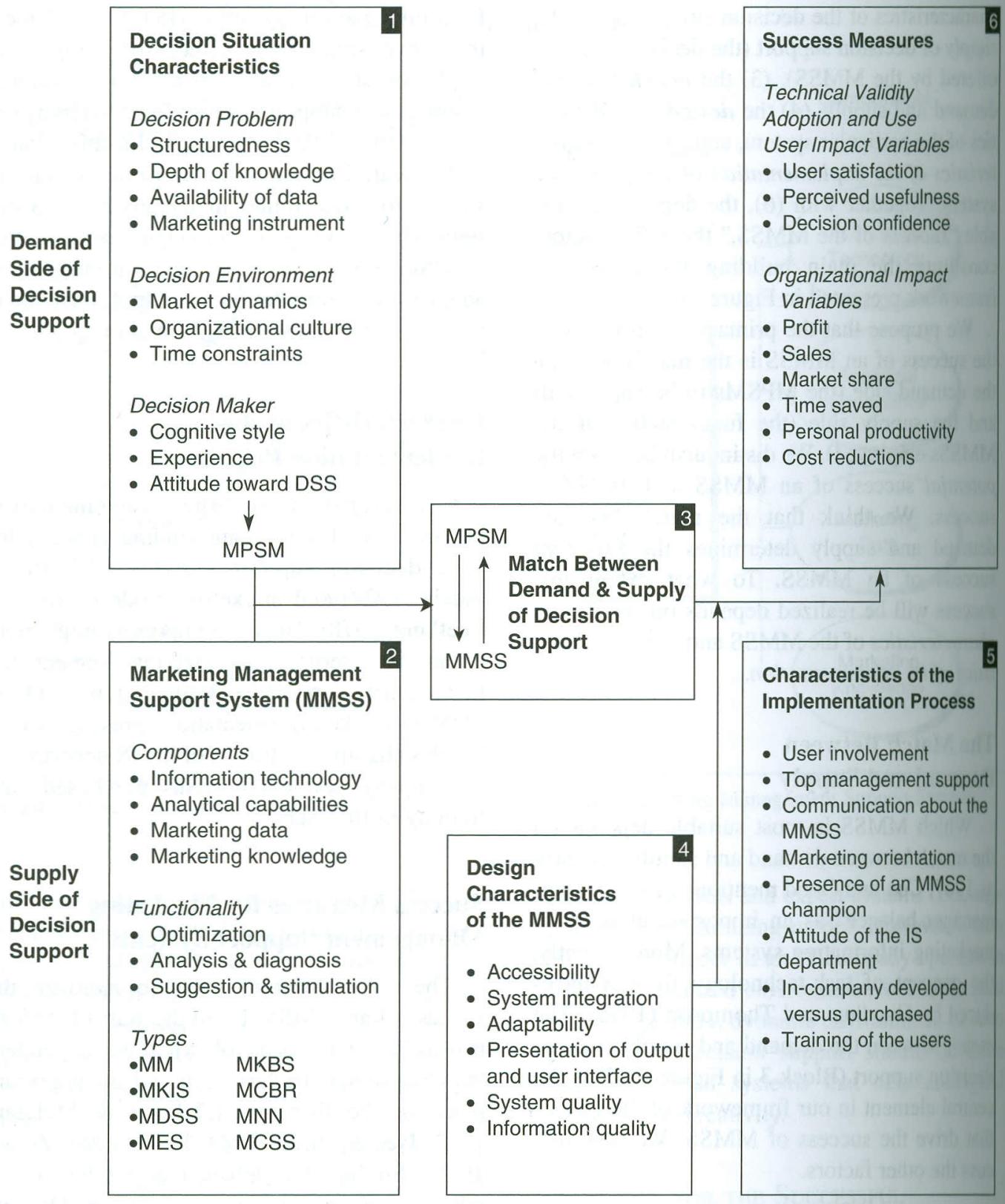

Figure 31.7 An Integrating Framework of Factors That Determine the Success of the Implementation and Use of Marketing Management Support Systems

Source: Adapted from Wierenga, Van Bruggen, and Staelin (1999). Reprinted by permission. Copyright $\odot 1999$ The Institute for Operations Research and the Management Sciences, Hanover, MD.

technically advanced systems may not be accepted by the decision maker. Therefore, the next success measure is adoption and use, which are also (obviously) necessary for the success of an MMSS. If a system is not both adopted and used, it cannot possibly be successful.
Regarding the impact of an MMSS, we follow DeLone and McLean (1992) in distinguishing between (individual) user impact variables and organizational impact variables.

User impact variables refer to how well the MMSS performs in the perception of the user. By 
far, the most frequently measured dependent variable in DSS/IS research is user satisfaction. Of 39 studies considered in a meta-analysis, $27(69 \%)$ had user (information) satisfaction as a dependent variable (Gelderman, 1997). Sometimes, slightly different concepts are used to express the user's psychological assessment of a system, such as perceived usefulness of a system (Adams, Nelson, \& Todd, 1992; Davis, 1989). Besides studying the evaluation of a system as such, one can also study the effects the MMSS has on the evaluation of behavior. A variable measuring behavior evaluation is decision confidence (Aldag \& Power, 1986; Goslar, Green, \& Hughes, 1986).

Organizational impact variables such as profit, sales, and market share have a more objective character. Ultimately, the costs of an MMSS should be outweighed by the extra profit it generates. Prior to that evaluation, one could examine the effects of an MMSS on sales and market share. It may be difficult to assess the profit contribution directly attributable to an MMSS. Sometimes, when it is not possible to determine the MMSS's contribution to overall company performance, more limited performance measures have been used in the DSS/IS literature. Examples of such measures are time saved, increased personal productivity, and cost reductions achieved by using the system, for example, in production scheduling and ordering costs (DeLone \& McLean, 1992). The impact of an MMSS on the user does not necessarily coincide with its impact on the organization. Goal congruence between the two does not always exist. Individual employees may use computer systems just for fun (Davis, Bagozzi, \& Warshaw, 1989), for providing (erroneous) information as a means of justifying poor decisions (Ives, Olson, \& Bouroudi, 1983), to increase the power of oneself or of the department (Markus, 1983), or just to impress others. In such cases, computer systems may serve the personal goals of employees, which can contradict or undermine the goals of the organization.

\section{Marketing Management Support Systems And Marketing ResEarch}

We now discuss the role of marketing research with respect to marketing management support systems. In doing this, our focus is on the internal marketing researchers (to be distinguished from marketing researchers from marketing research agencies) - that is, the people in the company who have the job to collect relevant information about markets, products, consumers, competitors, and distribution channels and make this available for marketing management. Many companies have specialized marketing research departments. In other companies, marketing research is part of the marketing department, or marketing research is organized in some other way.

The role of marketing research with respect to marketing management support systems depends on the specific type(s) of MMSS. We will elaborate on this below.

\section{Data-Driven Marketing Management Support Systems}

Traditionally, marketing research departments have played an important role in the collection and interpretation of marketing data. What is the contribution of marketing research to data-driven MMSS?

For marketing models, marketing research can contribute in three ways.

1. Provide the data that are necessary for the development and use of marketing models. Data are needed for the estimation of the parameters of marketing models, but most often, data also serve as input during the ongoing use of the model. For example, in the case of a predictive analysis model for direct marketing, the model will be estimated with data from customers with known purchasing histories. Subsequently, during its use, the model is fed with data from prospects whose purchasing probabilities are calculated. The data that marketing research makes available for marketing models can be internal company data or externally acquired data.

2. Serve as facilitator in the process of model building and implementation in the company. The actual building of marketing models often requires specialized expertise (econometrics, statistics, operations research, computer science). Dependent on its capabilities, the marketing research department can play a role here, but most often outside parties (e.g., consulting 
firms, universities) will do the main job. Instead of building a completely new model, software for marketing models can also be purchased as an off-the-shelf package from a vendor. In both situations, the marketing research department can play a role as an intermediary between the outside supplier and the marketing decision makers in the company. It can help with selecting the best-matching software and with making adaptations to the specific situation of the company.

3. Assist the users of the marketing model in the company (i.e., marketing decision makers) with interpreting the results and recommendations from the model and translating these into marketing actions.

To fulfill these roles with respect to marketing models successfully, the marketing research department should have the required knowledge and experience. This goes beyond what is often found in terms of expertise in traditional marketing research departments.

The second type of data-driven MMSS, marketing information systems (MKIS), is close to what has always been the territory of the marketing research department. Marketing researchers typically have not only given answers to ad hoc questions about consumers, products, and markets, but marketing researchers have since a long time (even before the arrival of the computer) been active in developing devices in which marketing data were systematically stored and made accessible to marketing managers. Therefore, the role of marketing research with respect to MKIS is very important. In modern times, marketing information systems are directly, online, accessed by marketing decision makers, and these should be able to find their way in the MKIS easily and with short response times. To realize userfriendly and effective MKISs, close cooperation is needed between the representatives of the marketing research department and the IT department of the company. In this team approach, marketing research has the primary responsibility for the nature and the quality of the marketing data in the system but should also have sufficient expertise about state-of-the-art information and communication technologies.
While MKISs are first of all used to answer the "what" question ("what happened?"), the third type of data-driven MMSSs - that is, market decision support systems (MDSSs)have the function to answer the "what-if" question. With MDSS, we go from "status reporting" to "response reporting" (Little, 1979). An MDSS is relatively close to the marketing decision maker. The manager can model the marketing phenomena according to his or her own ideas (mental model). Like MKIS, MDSSs are typically used online (i.e., through desktop or laptop computers). In 1979, Little mentioned the need for "marketing science intermediaries," analysts who would receive the questions from the marketing decision maker, actually work with the MDSS, and then return to the marketing decision maker with the answers. Given the complete integration of the computer and the Internet in the day-to-day activities of marketing decision makers, there does not seem to be a need for such intermediaries anymore. ${ }^{3}$ Nowadays, most managers are highly familiar with working with databases and systems. Given that marketing decision makers are in the driving seat themselves, the role of marketing researchers with respect to MDSS is limited. They can help to make sure that the data that the managers use for their analyses are available. Also, marketing researchers can assist decision makers with developing their MDSS. Not too complex MDSSs can easily be built in spreadsheet environments, and the marketing department can assist here. Sometimes, MDSSs come from outside (e.g., from data suppliers who also provide software to carry out manipulations with the data). The marketing research department (together with the IT department) may be instrumental in getting those systems installed and used by the marketing decision makers.

\section{Knowledge-Driven Marketing Management Support Systems}

The connection of marketing research with knowledge-driven MMSS is much weaker than with data-driven MMSS. Technologies such as expert systems, case-based reasoning, and creativity support systems are relatively new for the marketing research community. Marketing research departments have to decide whether 
they will also play a role in these new types of MMSS (which will require investments in the needed expertise and experience) or if they will leave this to other parties (e.g., the marketers themselves, the computer department, or external suppliers). The choice will depend on how marketing researchers see their mission: delivery of marketing data or contributing to the quality of marketing decision making in all respects.

Not only because of knowledge-driven MMSS should marketing researchers think beyond marketing data and also pay explicit attention to marketing knowledge. It should be realized that marketing decision makers not only use data-based analytical reasoning for making decisions but that (tacit) knowledge also plays an important role. Hogarth (2001) distinguishes two human systems of making judgment: the deliberate (or analytical) system and the intuitive (or tacit) system. Given time constraints, the majority of managerial decisions will probably be made under the intuitive system, for which the knowledge-driven MMSSs are meant to provide support. (The data-driven MMSSs are in the realm of the deliberate system.) For the intuitive system, the quality of (tacit) knowledge is of major importance. Marketing research has the task of providing a constant stream of high-quality, relevant marketing information that may not be immediately used for actual decisions but that feeds into the managers' intuitive system and contributes to the quality of future decisions made by this system. This is always an important responsibility of the marketing department, as well as when a company does not have specific knowledgedriven MMSS in place to support intuitive decision making.

\section{Marketing Researchers and MMSS in Competition?}

Market researchers have not typically taken the lead in developing MMSS in companies. A reason for that may be the fear that MMSS will take over functions that have traditionally been performed by marketing researchers. Marketing researchers may have enjoyed their position as the monopolist of marketing information to which they were the exclusive entrance. This position has ended with the arrival of MMSS, particularly with the directly connected marketing manager through the PC and Internet. Marketing researchers should reflect on their role in the new situation. They should not perceive MMSSs as their competitors but as partners in their mission to serve and support marketing decision makers and take marketing decision making in the company to the highest possible quality level. Earlier, we gave some indications about the roles that marketing researchers can play in this context.

Marketing researchers should realize that marketing decision makers, whom they support, may be different in their way of operating and decision making than they themselves are. Marketing researchers tend to emphasize uncertainties and probabilities, but (marketing) managers tend to think in terms of yes or no, rather than in probabilities (Little, 1970). Different from marketing researchers, they prefer to obtain straight answers to clearly articulated questions instead of doing exploratory research. Also, managers do not appreciate the interaction between managers and marketing researchers as much as marketing researchers do (Deshpande \& Zaltman, 1984). Apparently, they want answers, without too much ado. Furthermore, marketing researchers are also less at ease than managers with using subjective information, for example, about the shape of marketing response functions, such as used in the decision calculus methodology (Little, 1970). The average marketing researcher is closer to a statistician, who is averse to using parameters that are not grounded on reliable and valid data estimation procedures. The manager, knowing that he or she has to make a decision anyhow, is prepared to use any possible aid, even if this would imply accepting certain risks (e.g., making policy simulations with subjectively estimated parameters). When assisting managers with using MMSS, it is important that marketing researchers are aware of these peculiarities of how marketing managers make decisions.

\section{Conclusion}

In this chapter, we have presented an overview of the marketing management support systems 
that are currently available to support marketers in their daily managerial and decision-making activities. We have also introduced a model that supports the effective implementation of such an MMSS within an organizational context. Such a model is important because several studies (i.e., Lilien, Rangaswamy, Van Bruggen, \& Starke, 2004) have shown that a good system as such will not automatically be used by marketers because they often have difficulties in recognizing the quality and value of these systems. A careful implementation process will stimulate the effective use of MMSS. Marketing management support systems make a significant contribution to the quality of marketing decision making. At the same time, the use of marketing management support systems has a significant effect on the position and role of the marketing researchers in companies. If marketing researchers adequately redefine their role in the new situation, MMSS and marketing research can work together for the benefit of the company.

\section{Notes}

1. We use the terms marketing manager, marketing decision maker, and marketer interchangeably throughout the text. All three terms refer to a marketing decision maker in the generic sense.

2. Surprisingly, the terminology of 1966 shows striking similarities to that of today.

3. Little's prediction was made before the PC era.

\section{REFERENCES}

Aaker, D. A. (1975). ADMOD: An advertising decision model. Journal of Marketing Research, 12, 37-45.

Adams, D. A., Nelson, R. R., \& Todd, P. A. (1992). Perceived usefulness: Ease of use and usage of information technology. A replication. Management Information Systems Quarterly, 16, 227-247.

Aldag, R. J., \& Power, D. J. (1986). An empirical assessment of computer-assisted decision analysis. Decision Sciences, 17(4), 572-588.

Althuizen, N., \& Wierenga, B. (2005). Designing sales promotion campaigns with analogical reasoning. In G. Troilo (Ed.), Proceedings of the 34th EMAC conference (pp. 91 + CD Rom). Milan, Italy: University of Bocconi.

Bass, F. M., Buzzell, R. D., Greene, M. R., Lazer, W., Pessemier, E. A., Shawver, D. L., et al. (Eds.). (1961). Mathematical models and methods in marketing. Homewood, IL: Irwin.

Brien, R. H., \& Stafford, J. E. (1968). Marketing information systems: A new dimension for marketing research. Journal of Marketing, 32, 19-23.

Bultez, A., \& Naert, P. (1988). "SH.A.R.P.: Shelf allocation for retailers' profit. Marketing Science, 7(3), 211-231.

Burke, R. R. (1991). Reasoning with empirical marketing knowledge. International Journal of Research in Marketing, 8(1), 75-90.

Buzzell, R. D. (1964). Mathematical models and marketing management. Boston: Harvard University, Division of Research.

Cox, D. F., \& Good, R. E. (1967). How to build a marketing information system. Harvard Business Review, 45(3), 145-154.

Crawford, C. M. (1997). New products management (5th ed.). Chicago: Irwin.

Davis, F. D. (1989). Perceived usefulness, perceived ease of use and user acceptance of information technology. Management Information Systems Quarterly, 13, 319-340.

Davis, F. D., Bagozzi, R. P., \& Warshaw, P. R. (1989). User acceptance of computer technology: A comparison of two theoretical models. Management Science, 35(8), 982-1003.

DeLone, W. H., \& McLean, E. R. (1992). Information systems success: The quest for the dependent variable. Information Systems Research, 3(1), 60-95.

Deshpande, R., \& Zaltman, G. (1984). A comparison of factors affecting researcher and manager perceptions of market research use. Journal of Marketing Research, 21, 32-38.

Dutta, S., Wierenga, B., \& Dalebout, A. (1997a). Case-based reasoning systems: From automation to decision-aiding and stimulation. IEEE Transactions on Knowledge and Data Engineering, 9(6), 911-922.

Dutta, S., Wierenga, B., \& Dalebout, A. (1997b). Designing management support systems using an integrative perspective. Communications of the ACM, 40(6), 70-79.

Eliashberg, J., \& Lilien, G. L. (1993). Handbooks in operations research and management science: Vol. 5. Marketing. Amsterdam: Elsevier Science. 
Esch, F. R., \& Kroeber-Riel, W. (1994). Expertensysteme fur die werbung [Computer aided advertising system]. Munchen: Verlag Franz Vahlen.

Forbus, K. (1988). Qualitative physics: Past, present and future. In H. Shrobe (Ed.), Exploring artificial intelligence (pp. 239-296). San Mateo, CA: Morgan Kaufman.

Frank, R. E., Kuehn, A. A., \& Massy, W. F. (Eds.). (1962). Quantitative techniques in marketing analyses. Homewood, IL: Irwin.

Gelderman, M. (1997). Success of management support systems: A literature review and an empirical investigation. Amsterdam: Thesis Publishers Amsterdam.

Goodhue, D. L., \& Thompson, R. L. (1995, June). Taks-technology fit and individual performance. MIS Quarterly, pp. 213-236.

Goslar, M. D., Green, G. I., \& Hughes, T. H. (1986). Decision support systems: An empirical assessment for decision making. Decision Sciences, 17(1), 79-91.

Hayes, P. (1985). Naïve physics 1: Ontology for liquids. In J. Hobbes \& B. Moore (Eds.), Theories of the commonsense world (pp. 71-107). Norwood, NJ: Ablex.

Hoch, S. J., \& Schkade, D. A. (1996). A psychological approach to decision support systems. Management Science, 42(1), 51-64.

Hofstadter, D. (1995). Fluid concepts and creative analogies: Computer models of the fundamental mechanisms of thought. New York: Basic Books/HarperCollins.

Hogarth, R. M. (2001). Educating intuition. Chicago: University of Chicago Press.

Holyak, K. J., \& Thagard, P. (1995). Mental leaps: Analogy in creative thought. Cambridge, MA: Bradford Book/MIT Press.

Ives, B., \& Olson, M. (1984). User involvement and MIS success: A review of research. Management Science, 30(5), 586-603.

Ives, B., Olson, M., \& Bouroudi, J. J. (1983). The measurement of user information satisfaction. Communications of the ACM, 26(10), 785-793.

Johnson-Laird, P. N. (1988). The computer and the mind: An introduction to cognitive science. Cambridge, MA: Harvard University Press.

Johnson-Laird, P. N. (1989). Mental models. In M. I. Posner (Ed.), Foundations of cognitive science (pp. 470-499). Cambridge: MIT Press.

Keen, P. G. W. (1980, December). Reference disciplines and a cumulative tradition. Proceedings of the First International Conference on Information Systems, pp. 9-18.

Kolodner, J. (1993). Case-based reasoning. San Mateo, CA: Morgan Kaufmann.

Kotler, P. (1966). A design for the firm's marketing nerve center. Business Horizons, 9, 63-74.

Kotler, P. (1971). Marketing decision making: A model-building approach. New York: Holt, Rinehart \& Winston.

Kroeber-Riel, W. (1993). Computer-aided globalization of advertising by expert systems. In G. J. Bamossy \& W. F. van Raaij (Eds.), European advances in consumer research (Vol. 1, pp. 110-117). Amsterdam: Association of Consumer Research.

Lilien, G. L., Kotler, P., \& Moorthy, K. S. (1992). Marketing models. Englewood Cliffs, NJ: Prentice Hall.

Lilien, G. L., Rangaswamy, A., Van Bruggen, G. H., \& Starke, K. (2004). DSS effectiveness in marketing resource allocation decisions: Reality vs. perception. Information Systems Research, 15(3), 216-235.

Little, J. D. C. (1970). Models and managers: The concept of a decision calculus. Management Science, 16, B466-B485.

Little, J. D. C. (1975a). BRANDAID: A marketingmix model: Part 1. Structure. Operations Research, 23(4), 628-655.

Little, J. D. C. (1975b). BRANDAID: A marketing-mix model: Part 2. Implementation, calibration, and case study. Operations Research, 23(4), 656-673.

Little, J. D. C. (1979). Decision support systems for marketing managers. Journal of Marketing, 43, 9-26.

Little, J. D. C., \& Lodish, L. M. (1969). A media planning calculus. Operations Research, 17, 1-35.

Lodish, L. M. (1971). CALLPLAN: An interactive salesman's call planning system. Part 2. Management Science, 18(4), 25-40.

Markus, M. L. (1983). Power, politics and MIS implementation. Communications of the $A C M$, 26(6), 430-444.

McCann, J. M., Lahti, W. G., \& Hill, J. (1991). The brand manager's assistant: A knowledge-based systems approach to brand management. International Journal of Research in Marketing, $8(1), 51-73$.

McIntyre, S., Achabal, D. D., \& Miller, C. M. (1993). Applying case-based reasoning to forecasting retail sales. Journal of Retailing, 69(4), 372-398. 
Montgomery, D. B., Silk, A. J., \& Zaragoza, C. E. (1971). A multiple-product sales force allocation model: Part II. Management Science, 18(4), 3-24.

Naert, P. A., \& Leeflang, P. S. H. (1978). Building implementable marketing models. Leiden: Martinus Nijhoff.

Rangaswamy, A. (1993). Marketing decision models: From linear programs to knowledge-based systems. In J. Eliashberg \& G. L. Lilien (Eds.), Handbooks in operations research and management science: Vol. 5. Marketing (pp. 733-771). Amsterdam: North Holland.

Reinartz, W. J., \& Kumar, V. (2000). On the profitability of long-life customers in a noncontractual setting: An empirical investigation and implications for marketing. Journal of Marketing, 64, 17-35.

Reinartz, W. J., \& Kumar, V. (2003). The impact of customer relationship characteristics on profitable lifetime duration. Journal of Marketing, 67, 77-99.

Riesbeck, C. K., \& Schank, R. C. (1989). Inside casebased reasoning. Hillsdale, NJ: Lawrence Erlbaum.

Schmitz, J. D. (1994). Expert systems for scanner data in practice. In R. C. Blattberg, R. Glazer, \& J. D. C. Little (Eds.), The marketing information revolution (pp. 102-119). Boston: Harvard Business School Press.

Schmitz, J. D., Armstrong, G. D., \& Little, J. D. C. (1990). Coverstory: Automated news finding in marketing. Interfaces, 20, 29-38.

Schultz, R. L., \& Slevin, D. P. (1972). Behavioral considerations in the implementation of marketing decision models. Proceedings Spring and Fall Conference AMA, pp. 494-498.

Silk, A. J., \& Urban, G. L. (1978, May). Pre-testmarket evaluation of new packaged goods: A model and measurement methodology. Journal of Marketing Research, 15, 171-191.

Silver, M. S. (1991). Systems that support decision makers: Description and analysis. New York: John Wiley.

Simon, H. A. (1979). Models of thought. New Haven, CT: Yale University Press.
Simon, H. A. (1995). Machine as mind. In C. Glymour, K. Ford, \& P. Hayes, Android epistemology (pp. 675-691). Menlo Park, CA: AAAI Press.

Sternberg, R. J. (1977). Intelligence, information processing and analogical reasoning: The componential analysis of human abilities. Hillsdale, NJ: Lawrence Erlbaum.

Urban, G. L. (1970). SPRINTER MOD III: A model for the analysis of new frequently purchased consumer products. Operations Research, 18, 805-854.

Wierenga, B., \& Oude Ophuis, P. A. M. (1997). Marketing decision support systems: Adoption, use and satisfaction. International Journal of Research in Marketing, 14(3), 275-290.

Wierenga, B., \& Van Bruggen, G. H. (1997). The integration of marketing problem-solving modes and marketing management support systems. Journal of Marketing, 61, 21-37.

Wierenga, B., \& Van Bruggen, G. H. (2000). Marketing management support systems: Principles, tools, and implementation. Boston: Kluwer Academic.

Wierenga, B., \& Van Bruggen, G. H. (2001). Developing a customized decision support system for brand managers. Interfaces, 31(3), S128-S145.

Wierenga, B., Van Bruggen, G. H., \& Staelin, R. (1999). The success of marketing management support systems. Marketing Science, 18(3), 196-207.

Wittink, D. R., Addona, M. J., Hawkes, W. J., \& Porter, J. C. (1988). SCAN*PRO: The estimation, validation, and use of promotional effects based on scanner data. Working paper.

Zinkhan, G. M., Joachimsthaler, E. A., \& Kinnear, T. C. (1987). Individual differences and marketing decision support systems usage and satisfaction. Journal of Marketing Research, 24, 208-214.

Zmud, R. W. (1979). Individual differences and MIS success: A review of the empirical literature. Management Science, 25(10), 966-975.

Zuboff, S. (1985, Autumn). Automate/informate: The two faces of intelligent technology. Organizational Dynamics, pp. 5-18. 